\title{
Professional Work of Computer Science Students and their Academic Achievements - Imagination vs. Reality
}

\author{
https://doi.org/10.3991/ijep.v8i1.7445 \\ Marek Milosz( $\left.{ }^{(}\right)$, Elzbieta Milosz \\ Lublin University of Technology, Lublin, Poland \\ m.milosz@pollub.pl
}

\begin{abstract}
Due to the rapid development of Information Technology in the EU and throughout the world, there is a lack of Computer Science specialists. This lack deepens due to the inability to educate an adequate number of graduates by universities. This phenomenon causes students of computer science to be sought and employed by companies. This may have a negative impact on the academic achievements of these students. The paper presents the results of questionnaire surveys of Computer Science students at all levels and years of study. The study was conducted over two consecutive years. The article presents the research methodology and comparative analysis of their results. On this basis, a deeper analysis of the data contained in the questionnaires was made to verify the reality of students' perceptions about the impact of their employment on their academic achievements. The self-assessment of the impact of employment on the study process by freshmen and other students was also compared.
\end{abstract}

Keywords—students' employment; academic achievements

\section{Introduction}

New technologies are increasingly used in society. They need more and more IT professionals and solutions developed by them. Ever more IT specialists are also needed to maintain already existing IT systems. By the end of the decade (i.e. 2020), more than 800,000 IT specialists will be needed in the European Union (EU) [1]. The number of IT graduates in the EU unfortunately decreases. In Poland there is already a shortage of over 50 thousand IT specialists [2]. The number of IT graduates is decreasing [2] at a rate of 5\% per year, and the number of 14,000 graduates each year in Poland does not guarantee the fulfilment of market demand [2]. The lack of specialists causes delays in the implementation of many IT projects [2] and increase in their costs. This is because salaries in the IT sector are rising.

In this situation, three tendencies can be observed as a result of market conditions. The first is the adaptation of university curricula to the needs of the labour market so that graduates are better prepared for work. Many universities, including the Lublin University of Technology (LUT), undertake such activities [3]-[5]. The second tendency is to increase the interest of candidates in IT majors. For example, in 2016, 
there were over 600 candidates for Computer Science at the LUT, and already over 850 candidates this year (i.e. 2017). The number of accepted candidates is also growing, for example from 225 in 2016 to nearly 280 in 2017 . The education process is quite long, so a third trend can be observed - the search by IT companies for employees among students. This leads to the phenomenon of taking up work by students during their studies [6]-[7].

Students' professional work causes their time to be divided between study and work. This division can significantly influence students' academic achievements, decreasing their academic performance and causing loss of interest in studies [8].

The study of the phenomenon of influence of CS students' professional work on the results of their studies does not produce unequivocal findings [8]. Some of them confirm a negative impact [9] and others a positive one [10]. Other studies do not give unambiguous results [11]-[18].

This problem is quite complex. If the fact (and the burden attached to it) of student employment has a negative impact on their academic achievements, then it can reduce the number of graduates.

The article consists of two main parts. The first, Section 2, presents the research methodology, the organisation of research in the two consecutive years of 2015 and 2016, the results and the resulting conclusions. The second part, Section 3, presents the results of a more detailed analysis of the data from the research conducted in 2016. This refinement was aimed at confirming the hypothesis that students' work did not negatively affect their academic performance and finding differences in the ratings between freshmen and their more experienced colleagues. The results are summarised at the end of the article. The possibility of further research into the relationship between students' professional work and the course of their studies is also indicated.

\section{Previous research and its results}

\subsection{Research thesis, hypotheses and model}

The problems identified in the introduction are highly relevant for Poland and its Lublin region. At the same time the LUT is a university that provides the highest number of graduates in the field of Computer Science in the region. Due to the current state of the problem, studies were conducted to analyse the impact of student employment on their academic achievements. These studies were carried out in 2015 [6] and repeated the following year [8].

The study was based on the thesis [6]: Start of employment by computer science students increases the motivation to study, but decreases study results.

On the basis of the thesis a research model (Figure 1) was developed. The model showed the relationship between the following factors [6]: study grades, study process, practicality, motivations and the economic necessity to work. In concretising the model, the following hypotheses were formulated [6]: 
H1. A large number of computer science students undertake employment during their studies.

H2. IT students take up work out of economic necessity.

H3. Starting professional work has a negative impact on the students' grades.

H4. Starting professional work has a significant impact on the process of study in the assessment of students.

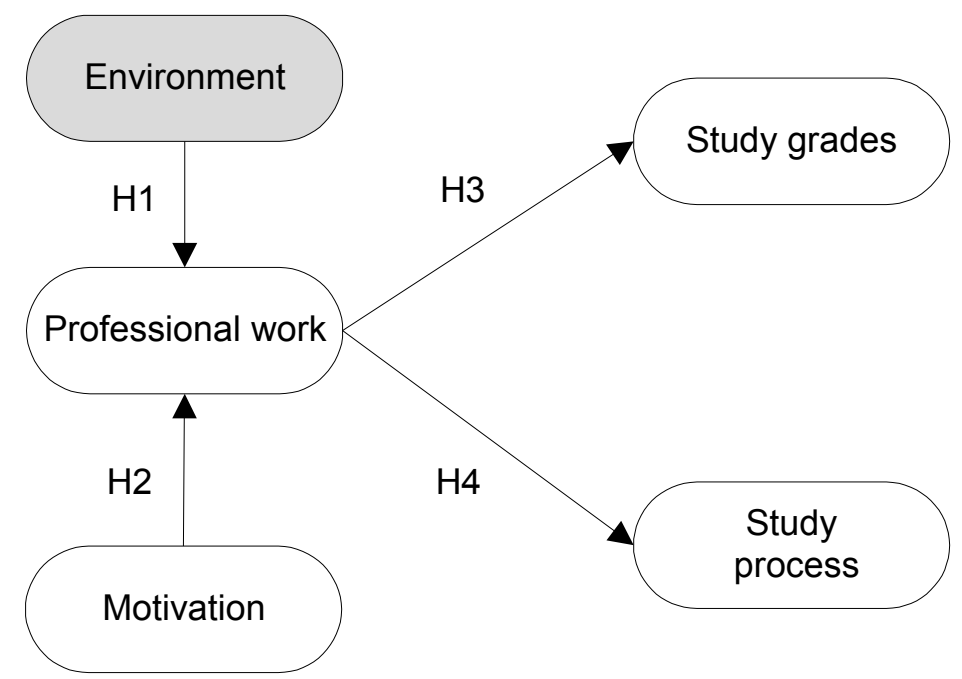

Fig. 1. The research model [6]

\subsection{Research carried out in 2015 and 2016}

In 2015 and 2016 studies were conducted to verify the hypotheses put forward. The research involved all CS students at the Lublin University of Technology. The research used a developed questionnaire and a paper-based method of obtaining answers. In 2015 , nearly $60 \%$ of all students were enrolled in the study. Depending on the semester of study, the response rate ranged from $43 \%$ to $78 \%$ of the total number of CS students. The research was repeated in 2016. It also had a high response rate from $60 \%$ to $96 \%$ of the total number of CS students.

The results of the research are shown in Figures 2-5. The percentage of working students increases during their studies and reaches over $40 \%$ in the last semester (Figure 2). A decline can be noticed in 2016 for graduate and 3rd semester students. From $28 \%$ to $37 \%$ (depending on the year of study), working students declare that their economic situation forced them to take up work during their studies (Figure 3). Over $50 \%$ (Figure 3 ) of working students indicate gaining practical experience and building their own $\mathrm{CV}$ as a reason for taking up a professional job. In contrast, very few (3-4\% - Figure 3) students indicate the prestige of professional work.

Working students have a fairly good academic achievement (Figure 4). They also declare, for the most part, that their work has no impact on study (Figure 5). 
Paper-Professional Work of Computer Science Students and their Academic Achievements - Imagi...

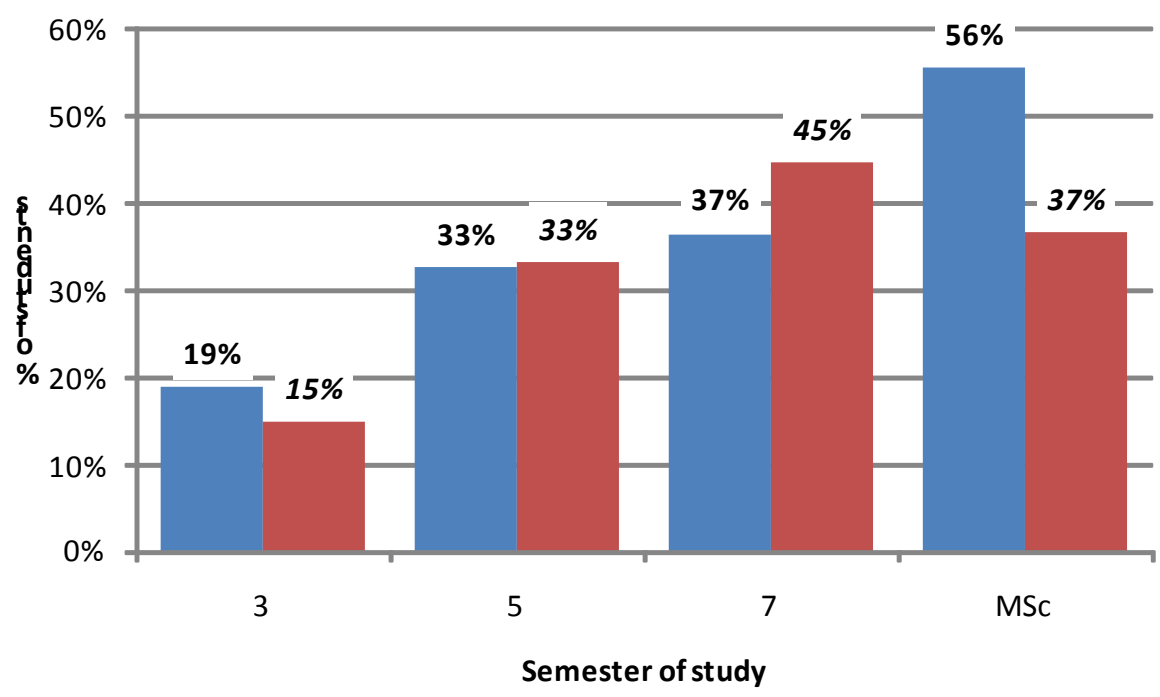

$2015 \square 2016$

Fig. 2. The rates of working computer science students at the LUT in the years 2015 and 2016 [8]

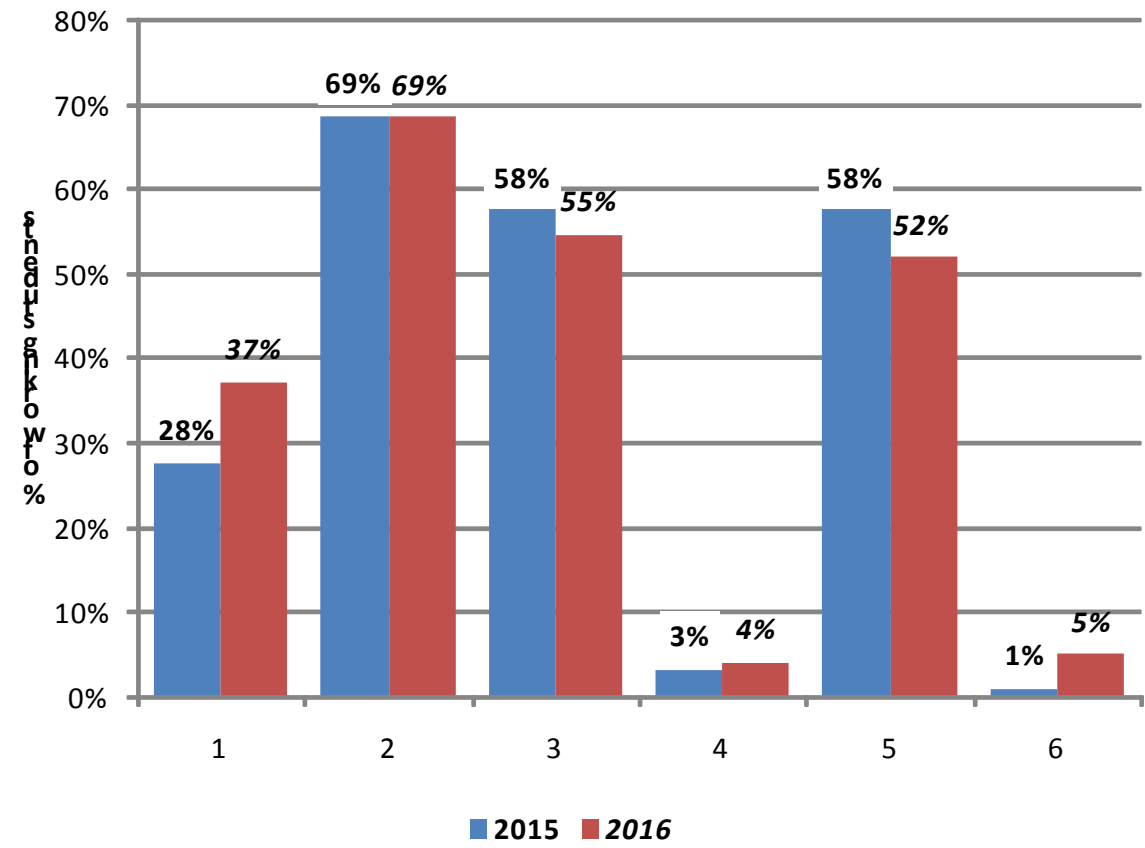

Fig. 3. The rates of CS students undertaking jobs for various reasons in the years 2015 and 2016 ( 1 - economic needs, 2 - desire to earn money, 3 - gaining practical experience, 4 - prestige, 5 - building own CV, 6 - other) [8] 


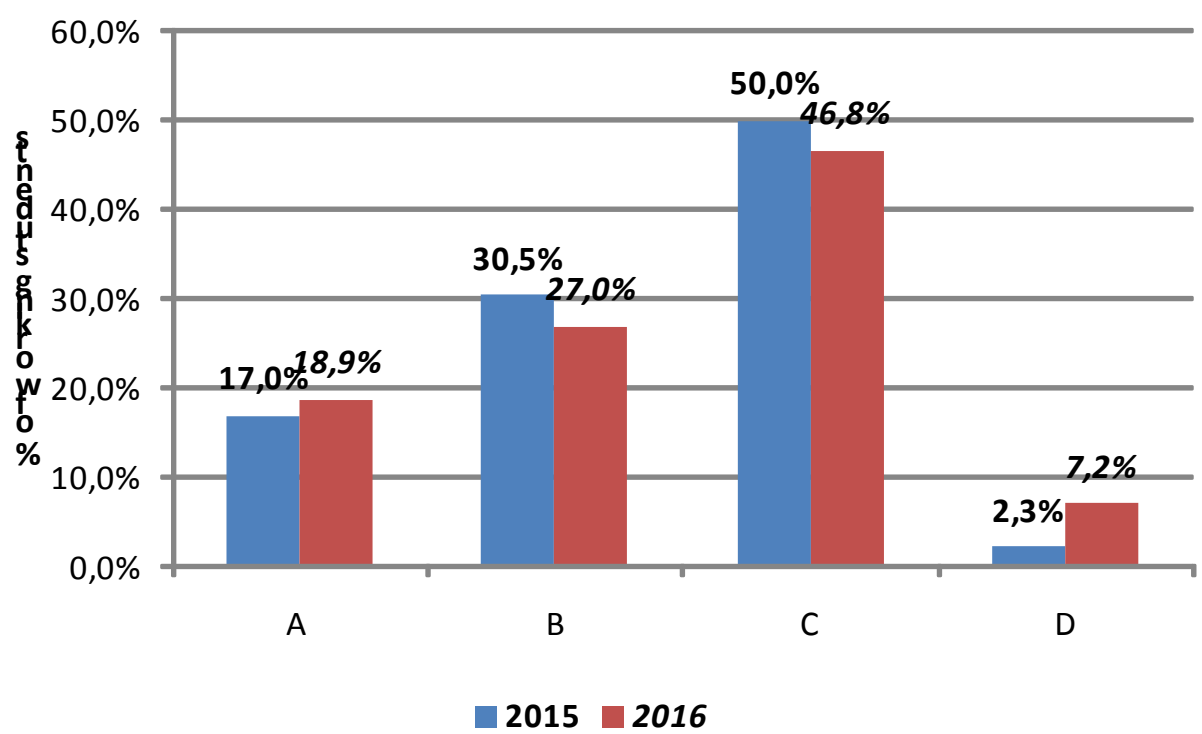

Fig. 4. Academic achievements of working CS students in the years 2015 and 2016 [8]

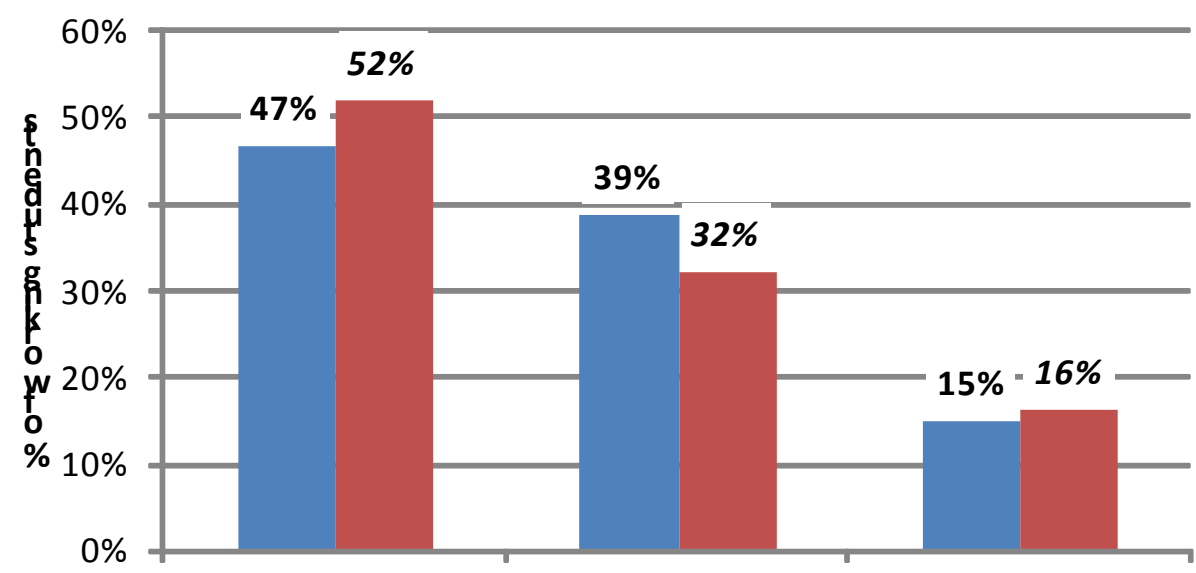

No effect Work interferes with Work helps in studies studies

\section{$2015 \square 2016$}

Fig. 5. Effect of the fact of professional employment on the process of study between 2015 and 2016 - students' self-assessment [8] 
Paper-Professional Work of Computer Science Students and their Academic Achievements - Imagi...

\subsection{Discussion and summarising of research results}

Both studies (i.e. of 2015 and 2016) gave roughly the same results.

Hypothesis H1, "A large number of computer science students undertake employment during their studies", has been fully confirmed. A large percentage of CS students are working. The percentage of those in work increases with the semester of studies.

Hypothesis H2, "IT students take up work out of economic necessity", has not been confirmed. A relatively small percentage of these workers would indicate this factor as important. More important is the desire to earn money and the factors inherent in the work itself.

Hypothesis H3, "Starting professional work has a negative impact on the students' grades", has not been confirmed. Working students have better academic achievements than those not working. The trend in the changes is not clear - the share of working students in rating groups A and D increased (compared to 2015), and decreased in groups B and C.

Hypothesis H4, "Starting professional work has a significant impact on the process of study in the assessment of students", turned out to be wrong. More and more students (in relation to 2015) indicate that work does not affect the process of study or has a positive effect. Also the percentage of students asserting that their work interfered with studies is also falling (from $39 \%$ to $32 \%$ ).

In addition, the following items related to students' professional work were assessed as positive [8]:

- developing skills of efficient time management,

- acquisition of the skills of creative problem solving,

- acquisition of social skills,

- acquisition of practical IT skills.

The negative effects of CS students are as follows [8]:

- absence from lectures,

- lack of time to participate in student activities,

- unwillingness to continue education at the next level,

- delay of project deadlines

\section{Professional work and academic achievement - more detailed analysis: 2016 research results}

\subsection{Motivation}

Research done in two successive years has not in principle confirmed the thesis. The students' work does not affect their evaluation, but also in the actual results, on the study process. This seems quite strange and may indicate the existence of the opposite relationship - better-performing students are more willing to be employed by 
employers and on better terms. This suspicion led to a more detailed analysis of survey data.

In 2016 students were also enrolled in 1 semester (freshmen). There was also a high response rate here - over $83 \%$ of the 223 students filled in the questionnaires. About $10 \%$ of freshmen work professionally, and most think that work does not affect their study. It was decided, by more accurate data analysis, to examine the differences between freshmen and other students.

\subsection{Self-assessment vs. reality}

Students in most cases assessed that professional employment did not affect the process of study (Figure 5). The percentage of such thinking students increased from $47 \%$ in 2015 to $52 \%$ in 2016 . In order to confirm the validity of the assessment, the academic achievements in 2016 were compared in two groups of students - those working and non-working. Statistics (Figure 6) confirm the lack of employment impact on student assessments, and even show that those who work achieve better performance. This is confirmed by the results obtained by other researchers, e.g. [10]. Among the top students (item A in Figure 6) are as many as 19\% of the employed and only $9 \%$ of the non-working students. Similarly, there are fewer working students in low academic achievement groups - groups $\mathrm{C}$ and D (Figure 6).

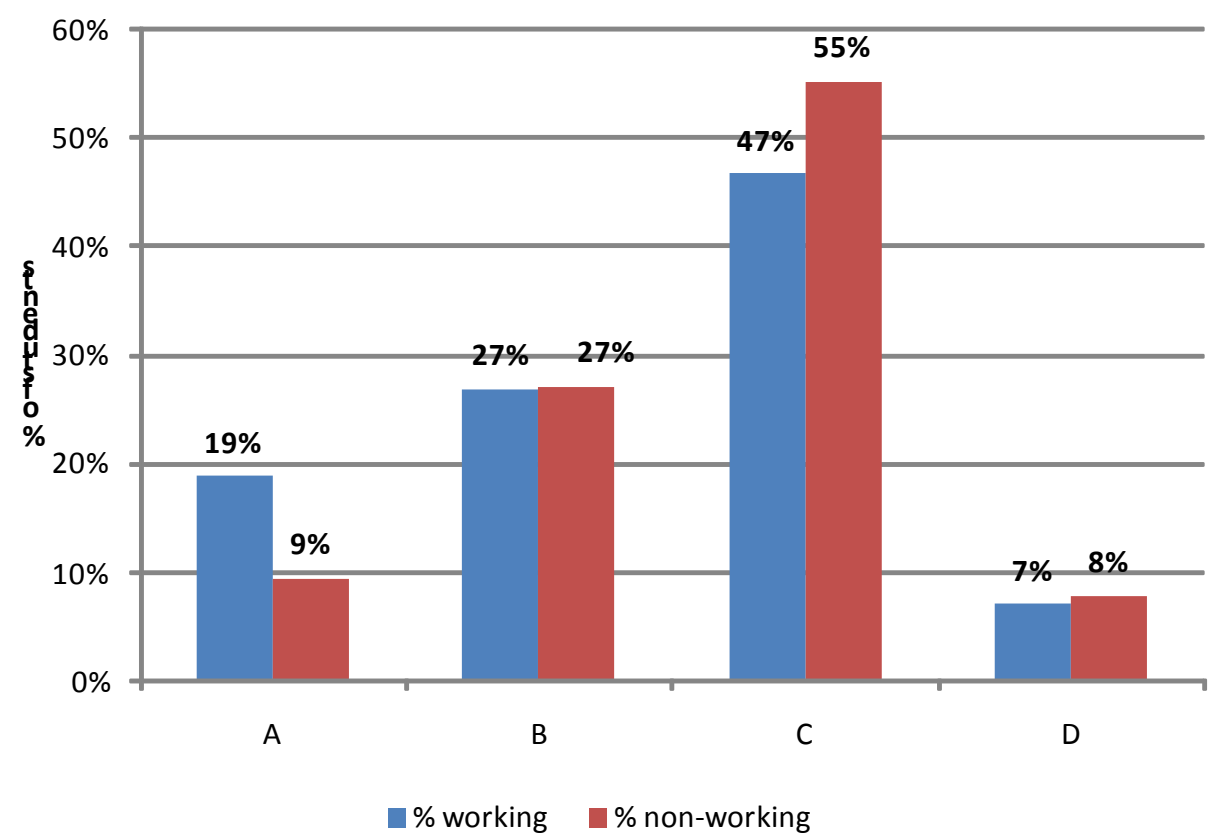

Fig. 6. The academic average grades of non-working and working CS students in 2016

Students who indicated that work did not affect their study process belong to the group of top students (Figure 7). But it should be noted that some of them are too 
optimistic about this aspect. This is shown by an above average proportion (58\% vs. $47 \%$ ) of their numbers in the weak student population (item $\mathrm{C}$ in Figure 7). A correct assessment of the impact of work on the course of study is also made by those students who find that work helps to study. Their representation is above average in groups A and B (Figure 7), and they are absent in the group of weakest students (item $\mathrm{D}$ in Figure 7).

Students' self-assessment of the influence of work on study is generally correct.

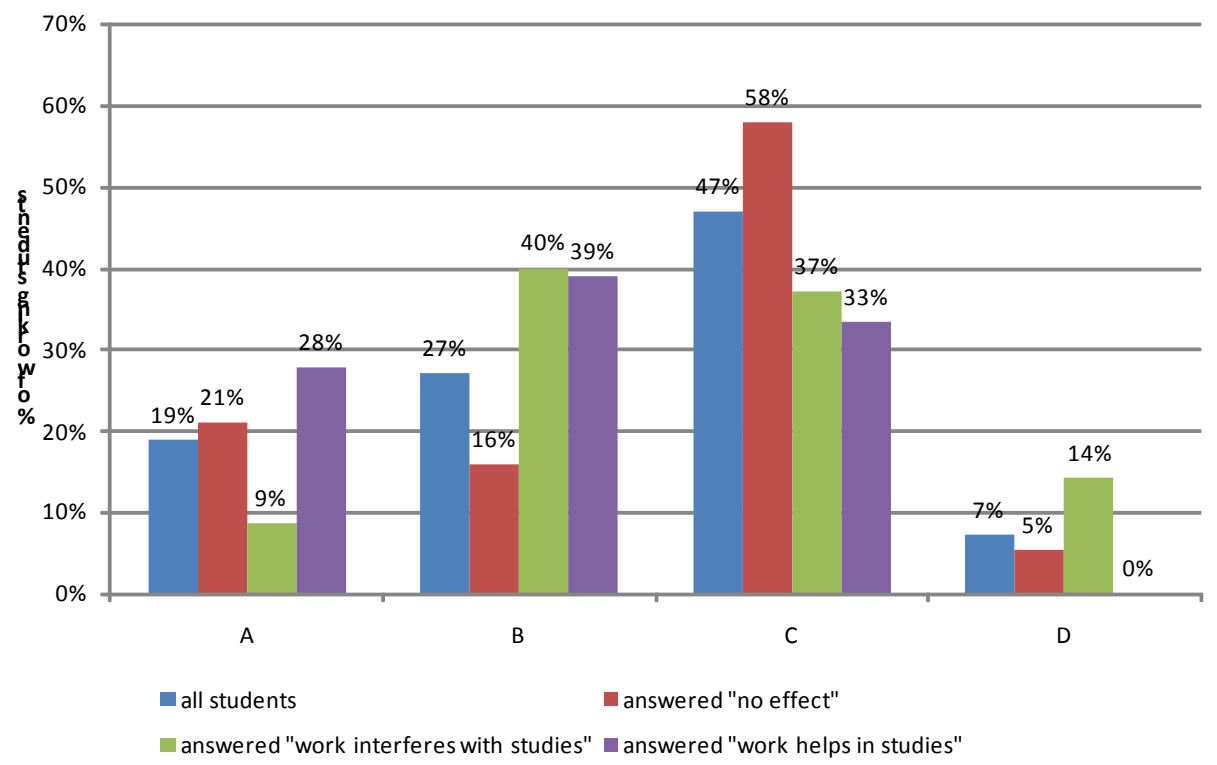

Fig. 7. Academic achievements of working CS students in the year 2016 - a comparison between groups of students indicating different effects of employment on the study process and all students

\subsection{Comparison of opinions between freshmen and other students}

A comparative analysis of the reasons for working between freshmen and other students is presented in Figure 8. Significant differences between the assessment of the reasons for employing students are found in two areas: "gaining practical experience" and "building own CV". Older students were more than twice as likely to point to these two causes than their youngest colleagues. This can be explained by the natural tendency of students to become aware of the demands of the labour market.

Figure 9 indicates that freshmen have a more optimistic approach to the impact of professional employment on the process of study. A very high percentage of them (79\% - Figure 9) declare no such impact. 


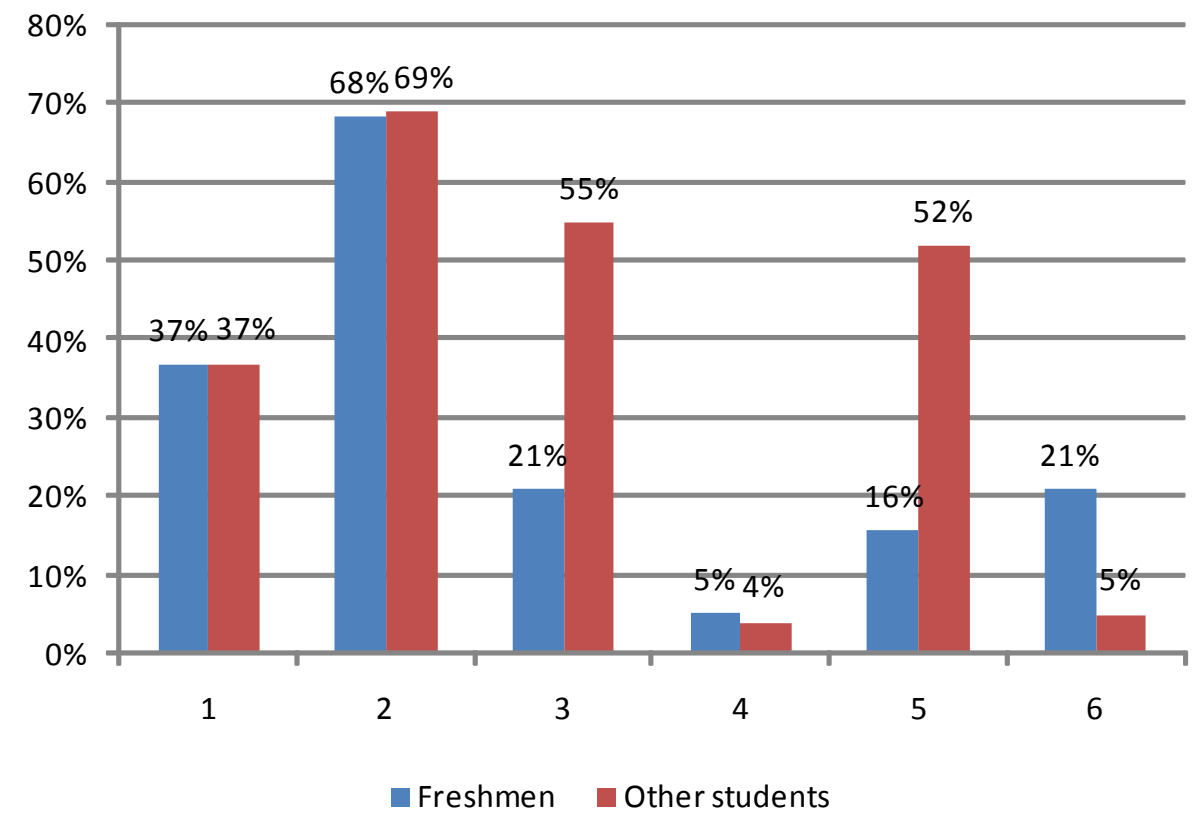

Fig. 8. The rates of CS students undertaking jobs for various reasons in the year 2016 - freshmen vs. other students ( 1 - economic needs, 2 - desire to earn money, 3 - gaining practical experience, 4 - prestige, 5 - building own $\mathrm{CV}, 6$ - other)

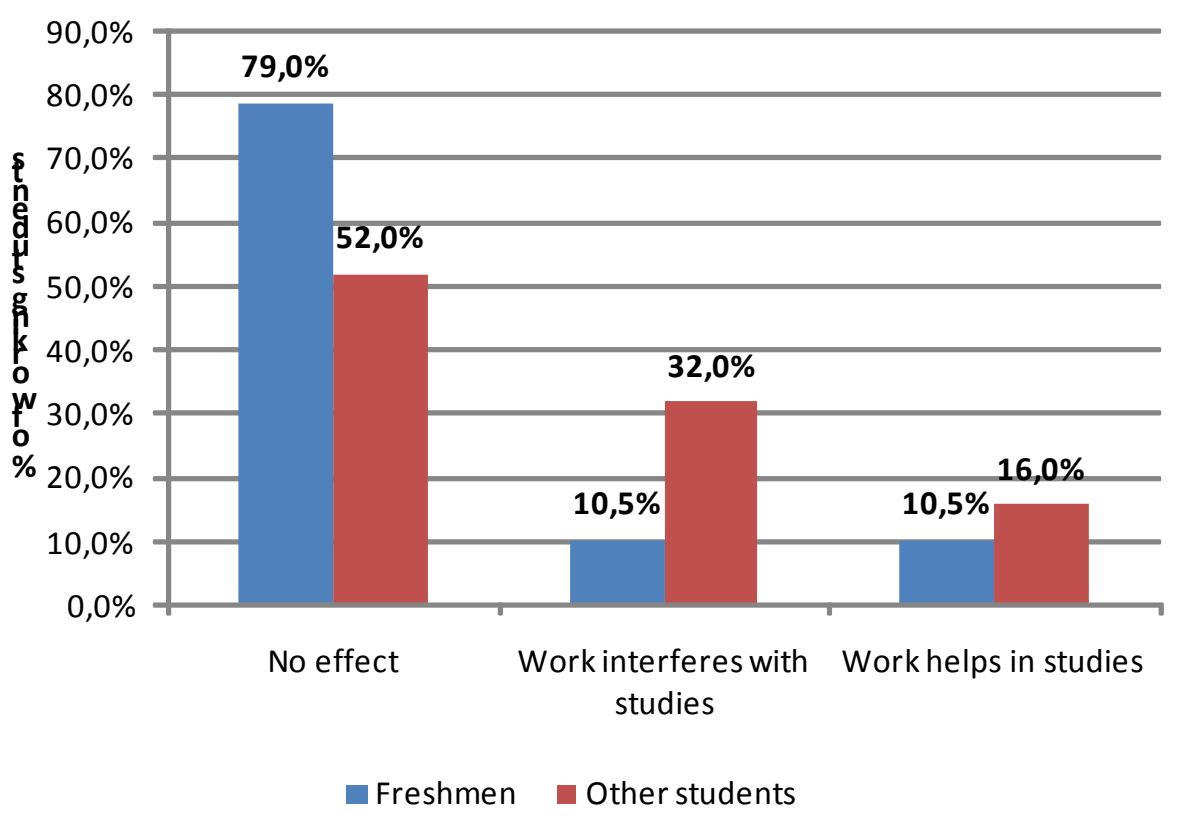

Fig. 9. Effect of the fact of professional employment on the process of study in the selfassessment by freshmen and other students 
Similar differences can be observed in assessments by freshmen and other students of the positive and negative aspects of employment - Figures 10 and 11 . The positive aspects of working as regards the area of social skills are similar in the assessment of working students in both groups (Figure 10, items: "acquisition of social skills", "developing the skills of efficient time management", and "acquisition of skills of creative problem solving"). Equally significant differences exist in the area of "acquisition of practical IT skills" and "acquisition of theoretical IT knowledge", which are more appreciated by older students.

Working freshmen assess hazards generally considerably lower than other students - Figure 11. Hazard areas such as "absence from lectures" or "lack of time to participate in student activities" were assessed nearly twice as low by freshmen as compared to the other students.

Such a change in the assessment perspective is undoubtedly due to the knowledge of the study process and the requirements of the labour market, as well as gaining experience in these areas.

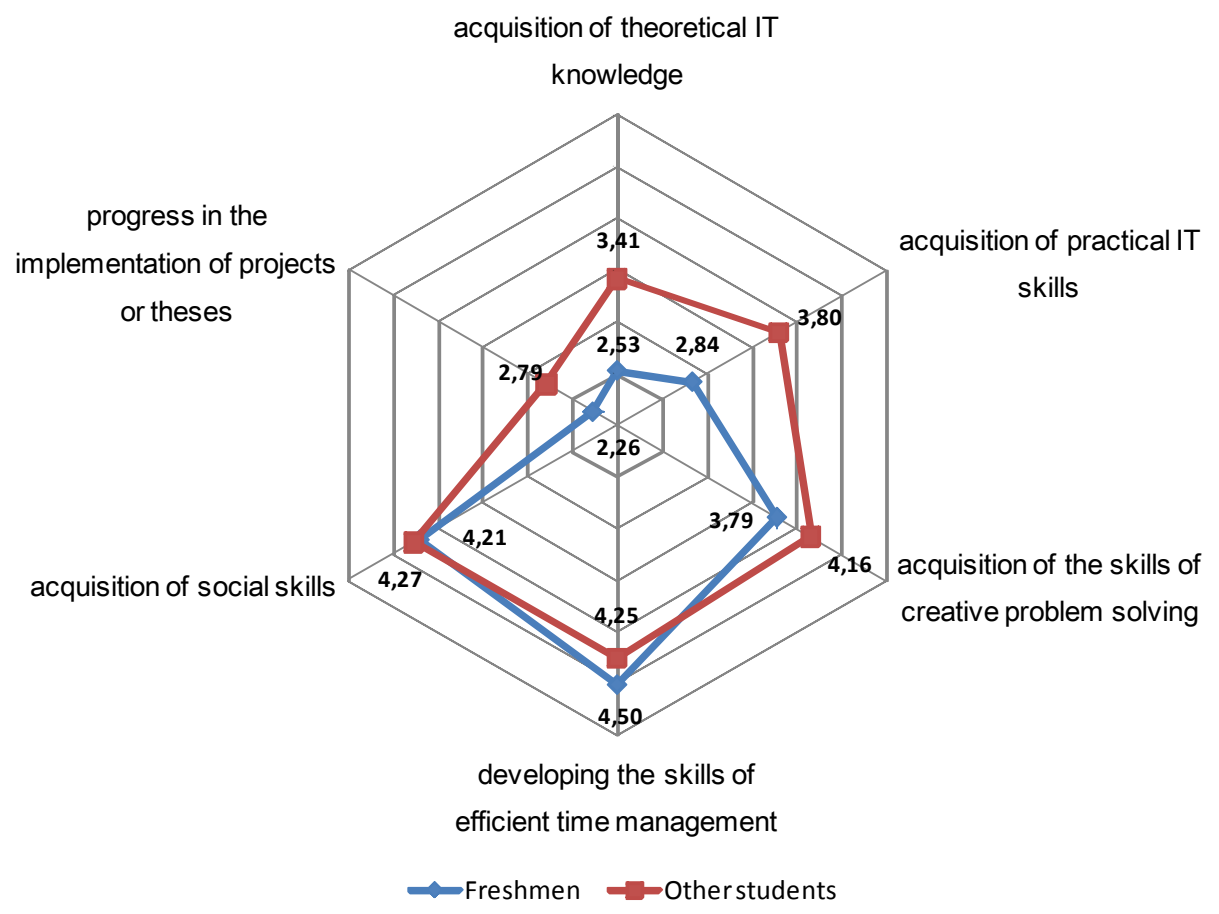

Fig. 10. The positive impact of work in the self-estimation of freshmen and other students in the year 2016 (the scale: 2 - no impact, ..., 5 - the highest impact) 


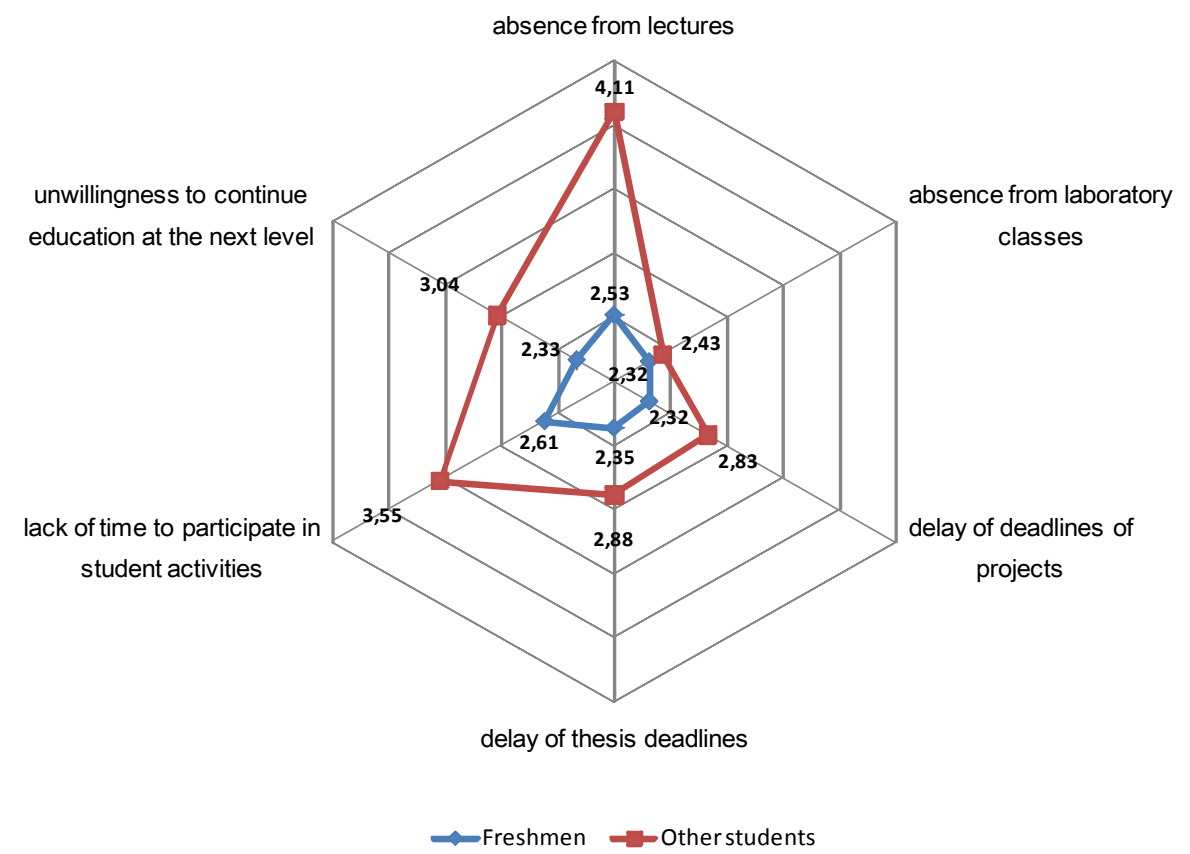

Fig. 11. The negative impact of work in the self-estimation of freshmen and other students in the year 2016 (the scale: 2 - no impact, ..., 5 - the highest impact)

\section{Conclusions and Future Works}

The research done in the years 2015 and 2016 did not fully confirm the thesis: "Start of employment by computer science students increases the motivation to study, but decreases study results". The study showed that students often take up work, while the percentage of working people increases with study time. In this way, Hypothesis 1 "Start of employment by computer science students increases the motivation to study, but decreases study results" can be considered proven. This cannot be said about the other three hypotheses. Economic necessity is not the single most important reason for students taking up employment (Hypothesis 2 "IT students take up work out of economic necessity"), just as there is no unequivocal negative impact of employment on students' academic performance (Hypothesis 3 „Starting professional work has a negative impact on students' grades"). Hypothesis H4 "Starting professional work has a significant impact on the process of study in the assessment of students", was partly confirmed, namely regarding the positive impact of students' professional work on their process of studying. According to a large proportion of students (from $47 \%$ to $79 \%$ ), the fact of professional employment has no effect on the process of study.

A more accurate analysis of the data obtained indicates a positive relationship of the work experience of students with their academic achievements. Working students generally have higher grades. Working students are right in assessing the impact of 
work on the study process. Those who assess that work helps in college have higher marks. Likewise, those who negatively evaluate this influence are right - they have a far worse academic achievement.

Freshmen are definitely more optimistic about their work situation. Unlike older students, they do not perceive many of the dangers (or diminish them), but the same goes also for the positive aspects of getting a job.

Research done over two years may not provide enough information for a proper analysis of the impact of student work on their studies. It would need to be repeated in 2017 and the following years. This would allow to analyse the problem's dynamics.

It would also be useful to expand the geographical area of research (by other Polish cities/regions and countries) and the type of university. The LUT is a technical university and its CS curriculum offered to students also has such a character.

Another study may focus on the analysis of individual students' career in terms of their academic achievements before and after taking up employment. However, this is not possible due to the anonymous nature of the survey.

\section{$5 \quad$ References}

[1] T. Hüsing, W. Korte, and E. Dashja, "E-Skills in Europe. Trends and Forecasts for the European ICT Professional and Digital Leadership Labour Markets (2015-2020)," Empirica Gesellschaft für Kommunikations- und Technologieforschung mbH, Bonn, Germany, November 2015, p. 42, http://eskills-lead.eu/fileadmin/lead/brochure-lead/working paper supply demand forecast 2015 a.pdf.

[2] http://www.biznes.newseria.pl/news/brakuje 50 tys,p109681472

[3] M. Milosz and E. Lukasik, "Reengineering of computer science curriculum according to technology changes and market needs," Proceedings of 2015 IEEE Global Engineering Education Conference (EDUCON), 18-20 March 2015, Tallinn, Estonia, pp. 689-693. https://doi.org/10.1109/EDUCON.2015.7096044

[4] E. Lukasik and M. Skublewska-Paszkowska, "University-industry cooperation as an extension of higher education offer," Proceedings of ICERI 2015: 8th International Conference of Education, Research and Innovation, 2015, Sevilla, pp. 3779-3785.

[5] G. Koziel and M. Milosz, "IT Studies and IT Industry - a case study," Proceedings of 6th International Conference on Education and New Learning Technologies (EDULEARN), 07-09 July 2014, Barcelona, Spain, pp. 5796-5802.

[6] M. Milosz, and E. Milosz, "Professional Work of Computer Science Students and its Impact on their Engagement and Academic Achievement", Proceedings of INTED 2016: 10th International Technology, Education and Development Conference INTED, 6-9 March 2016, Valencia, Spain, 2016, pp. 5179-5186. https://doi.org/10.21125/inted.2016. 0243

[7] M. Beerkens, E. Magi, and L. Lill, "University Studies as a Side Job: Causes and Consequences of Massive Student Employment in Estonia," Higher Education, vol. 61(6), 2011, pp. 679-92. https://doi.org/10.1007/s10734-010-9356-0

[8] M. Milosz, E. Milosz, "Pros and Cons of Computer Science Students' Professional Work Research results", Proceedings of IEEE Global Engineering Education Conference (EDUCON 2017), 25-28 April 2017, Athens, Greece, 2017 , pp. 10-16. https://doi.org/10.1109/EDUCON.2017.7942815

[9] K. M. Body, L. Bonnal, and J. Giret, "Does student employment really impact academic achievement? The case of France," Applied Economics, vol. 46(25), 2014, pp. 3061-3073. https://doi.org/10.1080/00036846.2014.920483 
Paper-Professional Work of Computer Science Students and their Academic Achievements - Imagi...

[10] D. Yanbarisova, "The Effects of Student Employment on Academic Performance in Tatarstan Higher Education Institutions," Russian Education \& Society, vol. 57(6), 2015, pp.459-482. https://doi.org/10.1080/10609393.2015.1096138

[11] S. Birdwell and A. Escovitz, "The Relationships between Student Employment During the Academic Year and Academic and NABPLEX Performance," American Journal of Pharmaceutical Education, vol. 54(2), 1990, pp. 117-120.

[12] G. R. Pike, G. D. Kuh, and R.C. Massa-McKinley, "First-Year Students' Employment, Engagement, and Academic Achievement: Untangling the Relationship between Work and Grades," NASPA Journal, vol. 45(4), 2008, pp. 560-582.

[13] M. Barber and J. Levitan, "Balancing the books: The impact of University Students' Outside Employment on Academic Performance and Emotional Well-Being," International Journal of Learning in Higher Education, vol. 21(3-4), 2015, pp. 14-19.

[14] M. Triventi, " Does Working During Higher Education Affect Students' Academic Progression?," Economics of Education Review, vol. 4, 2014, pp. 11-13.

[15] R. Darolia, "Working (and Studying) Day and Night: Heterogeneous Effects of Working on the Academic Performance of Full-time and Part-time Students," Economics of Education Review, vol. 38, 2014, pp. 38-50. https://doi.org/10.1016/j.econedurev.2013.10.004

[16] T. Kosi, B. Nastav, and J. Sustersic, "Does Student Employment Deteriorate Academic Performance? The Case of Slovenia," Revija za Socijalnu Politiku, vol. 20(3), 2013, pp. 253-274.

[17] A. Melilli, R. Mitola, and A. Hunsaker, "Contributing to the Library Student Employee Experience: Perceptions of a Student Development Program," The Journal of Academic Librarianship, vol. 42, 2016, pp. 430-437. https://doi.org/10.1016/j.acalib.2016.04.005

[18] A. Tur-Sinai, D. Romanov, and N. Zussman, "The true effect of students' employment on the duration of studies," Applied Economics, vol. 49(33), 2017, pp. 3328-3340. https://doi.org/10.1080/00036846.2016.1259749

\section{Authors}

Dr. Marek Milosz is a Deputy Director of Institute of Computer Science, Lublin University of Technology (LUT) and Head of Department of Software Engineering and Database Systems in this Institute. He is a lecturer and an expert in software engineering, human-computer interaction, database management, management information systems building and developing, IT solutions developing in e-business, project management, and serious games. He has very rich experience in practical usage of software engineering and project management. For 10 years he had been working as a project management trainer for IBM. He is active participant of many European projects as a coordinator of activities taken by LUT. He was supervisor app. 180 M.Sc. theses, most of them in software engineering field. He is an author or co-author 44 books and app. 350 scientific papers in computer science.

Dr. Elzbieta Milosz is a senior lecturer in Computer Science, Lublin University of Technology. She is a specialist on object oriented programming, software engineering, and e-business. She was supervisor app. 70 M.Sc. theses, most of them in software engineering and e-business fields.

This article is a revised version of a paper presented at the EDUCON2017 conference held in Athens, Greece, 25-28 April 2017. Article submitted 18 July 2017. Final acceptance 20 August 2017. Final version published as submitted by the authors. 